\title{
Evaluation of an Educational Programme to Facilitate Critical Thinking of Student Nurses
}

\author{
Louise Pretorius ${ }^{1 *}$, Hans Justus Amukugo', Agnes Van Dyk ${ }^{2}$, Louis F. Small ${ }^{1}$ \\ ${ }^{1}$ School of Nursing, Faculty of Health Sciences, University of Namibia, Windhoek, Namibia \\ ${ }^{2}$ School of Nursing, International University of Management, Windhoek, Namibia \\ Email: *lpretorius@unam.nam
}

How to cite this paper: Pretorius, L., Amukugo, H.J., Van Dyk, A. and Small, L.F. (2016) Evaluation of an Educational Programme to Facilitate Critical Thinking of Student Nurses. Open Access Library Journal, 3: e3064.

http://dx.doi.org/10.4236/oalib.1103064

Received: September 14, 2016

Accepted: October 28, 2016

Published: October 31, 2016

Copyright ( 2016 by authors and Open Access Library Inc.

This work is licensed under the Creative Commons Attribution International

License (CC BY 4.0).

http://creativecommons.org/licenses/by/4.0/

\begin{abstract}
This article deals with phase 4 of the study, namely the evaluation of the educational programme developed in phase 2 . The development of the educational programme was aimed at the facilitation of the development of critical thinking in the student nurse. The purpose of phase four (4) was to evaluate whether the researcher had achieved the objective of the educational programme, namely to facilitate the development of critical thinking skills of the final year student nurse. Specific objectives were therefore set for phase 4 . Further, hypotheses were formulated and tested during this phase of the study. The aim of formulating a hypothesis was to determine whether any development had taken place in the experimental group who participated in the educational programme. All fourth-year nursing students (47) who complied with the inclusion criteria participated in the educational programme. Each participant consented in writing to be part of the programme-including the pretest and posttest. A total of 53 students participated as the control group in the pretest and posttest. All the participants in the experimental and control groups of the study were registered for the Comprehensive Diploma in Nursing at the University of Namibia. Reasons were advanced in chapter 3 for the fact that the participants in the study were final-year students at the Windhoek and Oshakati campuses of the Faculty of Medical and Health Sciences. It was concluded that the implementation and evaluation of a three-day educational programme on the facilitation of the development of critical thinking within a quasi-experimental design had desired results. Students from both the main campus (Windhoek) and the Northern Campus (Oshakati) of the Department of Nursing at the Faculty of Medical and Health Sciences of the University of Namibia were included in the quasi-experiment. Internal validity of the design was ensured by eliminating the threats to an experimental design.
\end{abstract}

\section{Subject Areas}

Nursing 


\section{Keywords}

Evaluation, Educational Programme, Facilitate, Critical Thinking and Student Nurses

\section{Introduction and Background of the Study}

Teaching critical thinking has been identified as an important part of higher education, and similarly much has been said and written about the teaching of critical thinking in nursing. It is essential to highlight possible strategies for facilitating the teaching of critical thinking. In nursing, the challenge of teaching critical thinking is directed to the nurse educator, who must determine which method is best suited to his/her discipline. Many different teaching strategies exist, but they are not all suitable for facilitating the development of critical thinking.

The main focus of the teaching of critical thinking is to enhance active involvement by the learner, provide intellectual resources and to provide an environment conducive to the facilitation of critical thinking. In addition, the nurse educator has to model critical thinking to enhance the development of critical thinking in students [1] [2]. Another challenge to the nurse educator is to give students the chance to speak during teaching sessions and thereby reduce her own lecturing time. Most nurse teachers tend to talk too much, thereby giving the students less opportunity to speak and develop their critical thinking skills. The nurse educator must give the students more opportunities to speak, and thereby foster the development of critical [3] [4].

The provision of these opportunities begins with the creation of an environment in which threats and insults have no place. The atmosphere should provide psychological safety for the students. The nurse educator should listen attentively to the students and show them that she/he cares about their efforts. Since teaching of critical thinking in nursing education includes teaching in the clinical setting, a number of approaches can be employed to promote critical thinking in the clinical setting. The nurse educator should motivate the students to ask challenging questions during the care of patients, encourage students to justify or clarify their assertions, and grant them the opportunity to generate original and unconventional ideas, explanations or solutions to problems and model thoughtfulness while in contact with the students. However, continuous monitoring is essential during all these efforts to determine whether the students are progressing in their application of critical thinking skills in nursing practice and whether they understand their own learning in terms of critical thinking [2] [5].

A very effective way of teaching critical thinking is through the utilization of case scenarios. A case scenario is a realistic presentation of a client/patient case which encourages students to ask critical and probing questions. A case scenario also enhances active participation on the part of the students, especially when they have to deal with the case in a small group session. During the management of such a case scenario it is important that students should understand that one should not jump to conclusions 
but rather analyse the case to find the most suitable solution to the problem on hand [6].

The essence of teaching strategies that can facilitate critical thinking is to persuade the students to engage in reflection. Reflection is an action where the student can review, analyse or evaluate an experience or decision. A study by [7] revealed that the focus on reflection as a teaching strategy in the facilitation of critical thinking is ineffective. This resulted in the development of a model to enhance reflection and at the same time facilitate critical thinking.

Reflection can be related to any of the interventions employed during the scientific nursing process. For example, if the student admitted a client/patient it can be determined by reflection whether the admission was done comprehensively or whether more data is needed [2]. The development of an educational programme could enhance the application of critical thinking skills by individuals. [8] supports the statement by saying that a curriculum that will teach people to think is socially grounded and the logical product of a situational analysis. The author furthermore emphasized that it is essential for nurses to do research on how critical thinking can be developed in nursing practice to empower the nurse to render holistic care to clients/patients [9] [10] [11] expresses agreement by stating that critical thinking can be learned and even people who are talented in thinking can improve their thinking through education.

It can no longer be assumed that the care rendered by nurses is holistic; neither can they pretend to do their best in caring for their patients. Furthermore, nurses can no longer predict that what they learn today will serve them for a length of time, nor can they believe "that once we have finished a basic course we are adequately prepared for all future nursing situations" because of recent demands in the nursing profession [12] This emphasizes that nurses as professional adults require lifelong education to stay abreast of development and changes in knowledge and skills. In the light of the abovementioned statement, the researcher was convinced that the development and presentation of an educational programme could enhance the facilitation of critical thinking skills in student nurses. It is a fact that students who have never learned to think need to be taught how to think, how to arrange their ideas into a pattern, how to conceive and create and lastly how to remember what they have learned [3] [12] [13].

Moreover, it is the opinion of the researcher that because clinical time is limited, a condensed educational programme as will be discussed shortly, is imperative for the development of critical thinking skills in nursing practice. It is no longer a case of how academically smart and technically skilled candidates are, but rather how well equipped they are with a diversity of work-related skills, in this instance, nursing-related skills. When concrete practical examples are provided and integrated into teaching critical thinking, the groundwork is thereby laid for lifelong learning [14] [15].

Therefore, the development of such an educational programme is in line with the development of a curriculum which is defined as "formal and informal content and process by which learners gain knowledge and understanding, develop skills and attitudes, appreciations and values" [16]. The latter authors furthermore argued that de- 
signing a curriculum of any nature should be in line with the needs of the students and the community and that any curriculum holds a different promise for different groups of students [17] [18] [19] Finke \& Boland, 1998, p.117). Although the development of a programme differs somewhat from the traditional notion of the curriculum, it is certainly related to that. The notion of an adult education programme primarily connotes short-term learning experiences that are responsive to learner needs and that are delivered outside the traditional educational delivery system, with the emphasis not solely on content [18] [20] [21].

An educational programme is therefore designed to provide a sequence of learning experiences that will enable students to achieve desired outcomes as set by a Faculty. To formulate those outcomes, it should be asked what abilities are expected from the nurse [22]. The expected outcomes will direct the content of the programme as well as the mode of teaching that should be followed to achieve the outcomes set for the programme. It is furthermore assumed that any such programme should focus on and integrate desired competencies to be understood and applied within a given context. Competency is considered the ability to integrate knowledge, skills and abilities into actual practice [23] [24] [25].

Since the curriculum for this study was formed with practical interests in view, it focused on the process through which the leaner (nursing student) and the teacher (facilitator) interact to give meaning to the world (nursing practice). Such a curriculum is referred to as "praxis" since it generates action between humans. Such action is made possible by the fact that the human brain is designed to interact in an either a positive or a negative way. Interaction, in class and nursing practice, stimulates critical thinking as a result of opportunities that are created during these discussions. These opportunities are important to the student nurse because they cultivate an inquiring mind and thereby stimulate critical thinking [17] [18] [23] [26].

[27] suggests that the following four ideas are vital to the successful development of a programme, namely systematic process, daily practice, system flow and "mental to automatic"). Firstly, the systematic process delivers desired results which in the case of this research imply that students should have been able to apply critical thinking skills after going through a specific educational programme. Secondly, a programme should entail daily practice, namely nursing practice, and thirdly it should be part of the system so that it corresponds with the aspect of system flow. This educational programme complied with the last-mentioned ideas because it was developed within the Faculty of Medical and Social Sciences where the training of student nurses takes place. Fourthly, the last important requirement of a programme is the "mental to automatic" principle. This perfectly fits the concept of critical thinking since the ideal is to exercise critical thinking automatically after years of nursing practice. "Mental to automatic" refers to a point where a skill, not inborn or genetic, has been mastered [27]. Therefore, during the educational programme the student nurse was exposed to case scenarios that allowed him/her to practice the skill in order to facilitate the development of critical thinking skills [28]. 
For a programme that focuses on the development of critical thinking, one would aim to get participants actively involved in learning since active learning is more apt to stimulate higher cognitive processes such as those associated with critical thinking [24]. On this subject, [3] [12] is of opinion that "most teachers talk too much" and that learners can only participate if teachers allow them to. Critical thinking offers methods to transform students into active participants in their own intellectual growth. Educators must therefore shape their lecturing programmes to build skills and accommodate levels of self-directedness. Self-direction and interactive participation nurture and facilitate critical thinking [29] [30].

How critical thinking should be tested is a subject that has been debated for years. Since experts on critical thinking cannot agree on a definition for critical thinking there appears to be no single way to measure it accurately and to determine how it affects patient care. General measuring instruments are therefore not necessarily suitable for nursing and means should be found to measure critical thinking within the context of nursing practice. Evaluation can have different meanings for different people and can be interpreted in several ways. In all areas of nursing education and practice, evaluation is an important process that is used to measure learning and health-related outcomes [31] [32].

In previous nursing research that incorporated critical thinking tests, inconsistent relationships with decision making and clinical judgment were shown in addition to other inconsistencies related to critical thinking in nursing. Recommendations were then made that critical thinking tests should be adopted for nursing [33].

Therefore, for this study, the evaluation of the critical thinking skills of participants was adapted to fit the situation and to measure the achievement of the objectives of the study. Firstly a description of the participants of the educational programme is presented; secondly the outcome of the pretest results is compared with that of the posttest results in order to accept or reject the stated hypothesis. This is followed by a description of the results of an assessment on the presentation of the educational programme which is presented in the form of descriptive statistics. The evaluation of the educational programme forms the fourth and last phase of the study, although it is conducted consecutively with phase 3 . The outline and format of discussion be as follows: a supportive discussion on the evaluation of an educational programme as an activity in education; the methodology employed for phase 4 and Discussion of findings.

Evaluation is an important measure in nursing education and practice and it can be carried out for different reasons. For the purposes of this educational programme the following definition applies, namely that evaluation is the process whereby congruence of learner outcomes and educational programme objectives is determined. The sole basis for determining the success of an educational programme is to follow a holistic approach, to evaluate the provider's delivery of an educational programme and the participant's immediate experience [34] [35] considers evaluation to be the process that is conducted to provide feedback to the individual (educational programme developer) as well as feedback for administrative purposes. 
The most important function of feedback was to help participants learn to evaluate their own level of performance and focus their efforts to improve their skills. If an educational programme has made sense to a student and has elicited understanding at a personal level, it will become a lasting conceptual resource for that person. In order to establish whether an intervention has made a positive change, the researcher had to show two things: firstly that there has been a positive change over time and secondly that such a change is due to an intervention and not to extraneous factors [36]. The latter two conditions also applied to the evaluation of this educational programme.

As the researcher had different purposes in mind when carrying out the evaluation, the evaluation of the educational programme for this study was twofold namely to determine whether there had been a positive change in the participants' application of critical thinking skills, and whether that positive change was due to the educational programme and secondly, to assess the presentation of the programme. The second evaluation entailed an assessment by participants of the presentation and facilitation of the educational programme itself.

\section{Purpose of the Study}

The purpose of phase four (4) was to evaluate whether the researcher had achieved the objective of the educational programme, namely to facilitate the development of critical thinking skills of the final year student nurse. Specific objectives were therefore set for phase 4 .

\section{Objectives of the Study}

The following objectives were set for this phase, namely to

- conduct a posttest after the third day of the educational programme in order to evaluate the application of critical thinking skills by the participant (the student nurse) in the management of a problem case in nursing practice;

- compare the results of the pretest with the results of the posttest in order to determine whether there is a difference between the results of the pretest of the experimental group compared to the results of the posttest of the experimental group;

- compare the mean scores of the experimental group with the mean scores of the control group;

- test the stated hypothesis to determine if the participants have changed as a result of attending the educational programme;

- allow participants to assess the presentation of the educational programme in order to detect whether some changes in the presentation of the educational programme need to be introduced by the researcher.

\section{Methodology}

The researcher aimed to determine whether the educational programme has succeeded or failed in the facilitation of the development of critical thinking skills and to ascertain how the participants valued the presentation of the educational programme. The evalu- 
ation of the educational programme was done to determine whether there was an improvement in the application of the critical thinking skills after they have attended and participated in the educational programme. This enabled the researcher to accept or reject the stated hypothesis. A hypothesis is a tentative prediction about the relationship between two or more variables in the population under study, and it predicts an expected outcome. The use of a hypothesis in a study induces critical thinking and facilitates the interpretation of data [37].

Formulation of the hypothesis was done as it illustrated in Table 1.

The instrument developed for this phase to conduct the post-test instrument developed in phase 3. The researcher also developed an assessment instrument which had to be used to assess the presentation of the educational programme and the opinion of the participants about the utilization of case scenarios as a strategy to facilitate critical thinking.

The questions asked on the case scenario were straightforward and focused on the main critical thinking skills that any participant (student nurse) at fourth-year level ought to have. It was expected that participants at that stage of their training would manage this case extremely well. The post-test served as parameter to determine whether their critical thinking skills have improved after attending the educational programme which aimed to facilitate the critical thinking of participants The total possible score for the case scenario was 59, of which the distribution of maximum marks per question was as follows on each concept: Evaluation: 12; Analysis: 8; Interpretation: 12; Inference: 8; Explanation: 4 and Self-regulation: 15.

Reliability and validity of the post-test were already established, in view of the fact that exactly the same case scenario was handed to the participants as in the pretest. The answer sheets were compared by referring to each participant's student number. Validity for the instrument on the program assessment was ensured through expert opinion and construct validity, as the questions related directly to the content of the educational programme.

Table 1. Hypotheses formulated for the evaluation of the educational programme.

Title

\section{Hypothesis 1:}

This hypothesis was formulated to test the difference between the mean scores in the pretest of the experimental and control groups.

\section{Hypothesis 2:}

This tested the difference in the mean scores between the pretest and posttest of the experimental group and the mean scores of the pretest and posttest of the control group.

\section{Hypothesis 3:}

This hypothesis was formulated to test the difference in the mean posttest scores of the control group and the experimental group.
Null and alternative hypothesis

$\mathrm{Ho}_{1}$ : There is no significant difference between the mean pretest scores of the control group and the experimental group with respect to the six critical thinking concepts.

$\mathrm{Ha}_{1}$ : There is a significant difference between the mean pretest scores of the control group and the experimental group with respect to the six critical thinking concepts.

$\mathrm{Ho}_{2}$ : There is no significant difference between the posttest and pretest mean scores of the experimental and control groups with respect to the six critical thinking concepts.

$\mathrm{Ha}_{2}$ : The difference between the posttest and pretest mean scores of the experimental group is significantly higher than the difference between the posttest and the pretest of the control group with respect to the six critical thinking concepts.

$\mathrm{Ho}_{3}$ : There is no significant difference between the mean posttest scores of the control group and the experimental group with respect to the six critical thinking concepts.

$\mathrm{Ha}_{3}$ : The posttest mean scores of the experimental group are significantly higher than the mean posttest scores of the control group with respect to the six critical thinking concepts. 
All fourth-year nursing students (47) who complied with the inclusion criteria participated in the educational programme. Each participant consented in writing to be part of the programme-including the pre-test and post-test. A total of 53 students participated as the control group in the pretest and posttest. All the participants in the experimental and control groups of the study were registered for the Comprehensive Diploma in Nursing at the University of Namibia. The participants in the study were final-year students at the Windhoek and Oshakati campuses of the Faculty of Health Sciences.

Data collection during phase 4 entailed the following: A post-test was conducted immediately after the educational programme had been concluded to ensure that no external variables influenced the students in answering the questions. It was important to exclude the interference of any other intervention such as other classes or training programmes until after the post-test in order to show that the difference, if any, in the performance of the students was due to the programme and not to something else (Babbie \& Mouton, 2001: p. 348). The researcher collected data from the experimental group but was assisted with the collection of data from the control group by a research assistant. A programme assessment was conducted after the post-test, which focused on the presentation of the programme and the utilization of case scenarios as a teaching strategy in the facilitation of critical thinking

The answers to the posttest were analyzed by means of a tested rubric and results were described by means of descriptive statistics. Although several validated standardized measuring instruments for critical thinking have been designed over the years, they are not contextual to nursing and there is consensus in nursing literature that the instruments do not adequately measure critical thinking in the nursing discipline [38] [39] and cannot simply be used in general to evaluate an exclusively designed educational programme to fit the Namibian nursing context. The evaluation instrument on which the answers of the case scenario were evaluated and rated was designed by the researcher to fit the content of the educational programme).

The aim of the post-test was to compare the results of each participant's posttest with the results of the pretest of the participant to indicate whether the student's performance had improved as a result of the educational programme on critical thinking. The results were analysed with the assistance of a statistician and by means of a t-test that formed part of the SPSS (Statistical Package for Social Sciences) computer software programme. A t-test is defined as the parametric statistical test for analyzing the difference between the mean scores of two groups [37]. The discussion of the findings will follow. The findings as displayed in the tables and figure have enabled the researcher to test the hypotheses as formulated in Table 1 . The evaluation of the programme specifically focused on the six main critical thinking concepts.

The participants were requested to complete the assessment of the programme presentation after completing the post-test. The aim of the programme presentation was to determine how the participants perceived the presentation of the programme and what their perceptions were regarding the utilization of case scenarios as a strategy to enhance critical thinking. The findings of this assessment will be discussed under findings 


\section{Findings}

To highlight or emphasize the meanings of the findings it was decided to present them as follows: the differences between the two groups by means of statistical testing, specifically t-test analysis; the exploration of these differences in a descriptive format by utilizing a table (see Table 1) and the presentation of graphs to demonstrate the differences in mean scores per critical thinking concept. The first discussion will be on the differences between the two groups, incorporating the testing of the stated hypotheses.

\section{Formulated hypothesis}

\section{Hypothesis 1}

This hypothesis was formulated to test the difference between the mean scores in the pretest of the experimental and control groups.

$\mathrm{Ho}_{1}$ : There is no significant difference between the mean pretest scores of the control group and the experimental group with respect to the six critical thinking concepts.

$\mathrm{Ha}_{1}$ : There is a significant difference between the mean pretest scores of the control group and the experimental group with respect to the six critical thinking concepts.

\section{Hypothesis 2}

This tested the difference in the mean scores between the pre-test and post-test of the experimental group and the mean scores of the pretest and posttest of the control group.

$\mathrm{Ho}_{2}$ : There is no significant difference between the post-test and pre-test mean scores of the experimental and control groups with respect to the six critical thinking concepts.

$\mathrm{Ha}_{2}$ : The difference between the posttest and pretest mean scores of the experimental group is significantly higher than the difference between the post-test and the pre-test of the control group with respect to the six critical thinking concepts.

\section{Hypothesis 3}

This hypothesis was formulated to test the difference in the mean post-test scores of the control group and the experimental group.

$\mathrm{Ho}_{3}$ : There is no significant difference between the mean posttest scores of the control group and the experimental group with respect to the six critical thinking concepts.

$\mathrm{Ha}_{3}$ : The post-test mean scores of the experimental group are significantly higher than the mean post-test scores of the control group with respect to the six critical thinking concepts.

For the comparison of the pre-tests of the two groups, both groups were compared to investigate the difference in the application of critical thinking skills during the management of a case scenario in the health setting. The scores for the pre-test and post-test of both the experimental and the control groups were analyzed by means of a t-test. No significant difference was expected between the means of the pretest scores of the two groups. In addition, the mean scores were compared to assess them for substantial differences. A substantial difference for this study is defined as a difference in mean scores of more than 5 . 
The pretest mean scores of the two groups did not differ statistically significantly in four concepts because the p-values were greater than 0.05 . In two of the concepts, the p-value for the pretest was $<0.05$, which implies that there was a difference in the pretest mean scores of the two groups. However, the difference in the mean scores of the posttest of the experimental group was significantly and substantially higher than the mean scores of the control group which "absorbed" the difference. The testing of hypothesis 1 therefore resulted in the following:

\section{Hypothesis 1 (Table 1)}

$\mathrm{Ho}_{1}$ is rejected in favour of $\mathrm{Ha}_{1}$ on the $5 \%$ level of significance. In four of the concepts no significant difference in the mean scores of the pretest of the experimental and control groups were found. A significant difference in the mean scores of the pretest of the experimental group and the pretest of the control group was determined in two of the six critical thinking aspects. However, the difference in the mean scores of the posttest of the experimental group and the mean scores of the posttest of the control group was also significantly and substantially higher.

Comparison of pretest and posttest mean scores of the experimental group and control group:

The statistical analysis of the mean scores of the two groups enabled the researcher to assess whether the educational programme had a positive effect on the experimental group. This was done to ascertain whether the participants showed any improvement between the pretest and the posttest. The implication that the two groups were initially on a similar level suggested that a significant statistical difference between the pretest and posttest scores of the participants of the experimental group would indicate development as a result of the application of the educational programme.

To rule out the threat to internal validity posed by the consideration that the experimental group might have been better from the start, it was established statistically that in the concepts analysis and inference the groups were not equal in the pretest. The experimental group scored higher than the control group in their pretest before they attended the educational programme. It was determined, however, that they also scored significantly and substantially higher in the posttest compared to the mean score of the control group. It can therefore be concluded that the difference between the pretest and the posttest of the experimental group on the concepts of analysis and inference is significant.

As indicated in Table 2 and Figure 3, a significant and substantial difference of more than 5 in the mean scores of the pretest of the experimental group was found in all six critical thinking concepts.

Figure 3 illustrates a graphical representation of the pretest and posttest scores of the two groups. This was of assistance in testing hypothesis 2 .

Table 2 illustrates T-test analysis of the pretest and posttest scores of the experimental and control group.

Hypothesis 2 (Table 1)

$\mathrm{Ho}_{2}$ is rejected in favour of $\mathrm{Ha}_{2}$ on the $2.5 \%$ level of significance $(\mathrm{P}<0.001)$ in all the 
Table 2. Means, standard deviation and P-values between pre- and post-test scores concerning the application of six main Critical thinking concepts [T-TEST ANALYSIS].

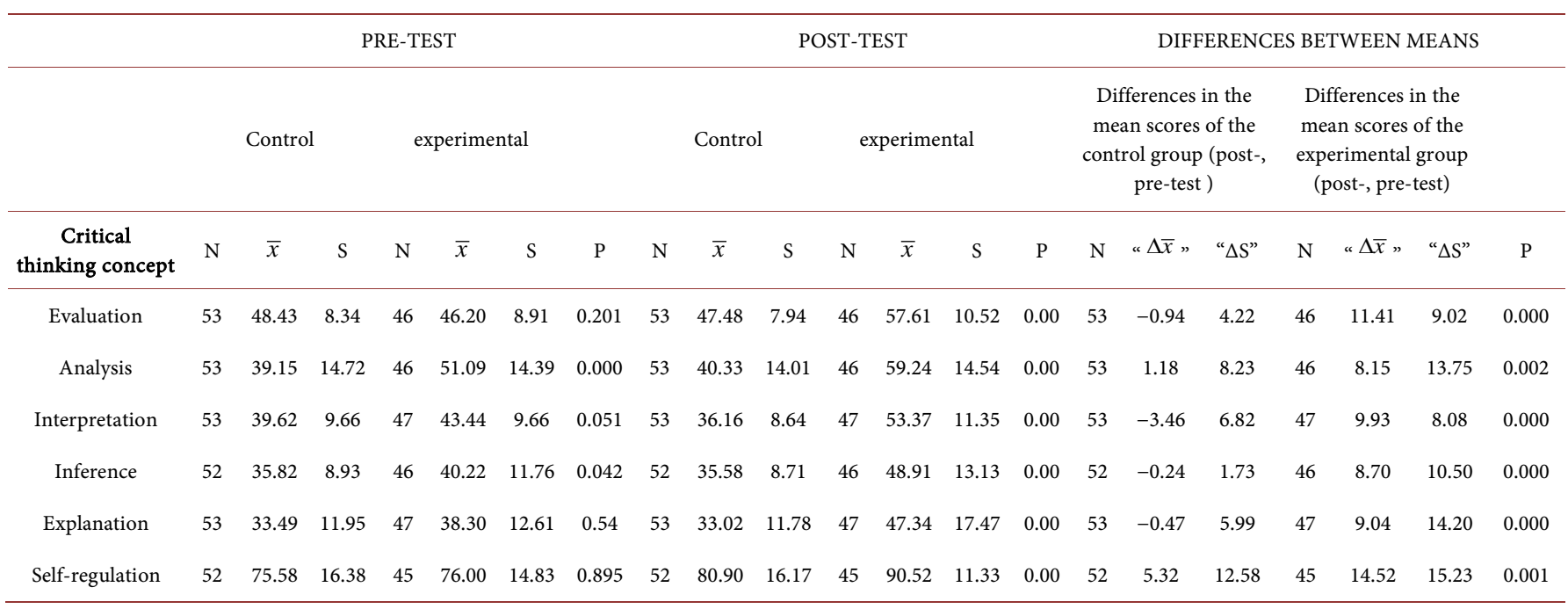

$(\mathrm{p}=0.000$ in SPSS is interpreted as $\mathrm{p}<0,001)$. “ $\Delta \bar{x}$ ”: difference in means; “ $\Delta \mathrm{S}$ ”: difference in standard deviation.

${ }^{* *}$ The population sizes are not the same for all six concepts as some participants did not answer all questions asked on the case scenario.

The few "missing answers could not influence the results significantly as the population size was of an appropriate size to do a proper analysis and the results of the questions answered was important in this study.

The total possible score 59 .

Score per concept: Evaluation 12; Analysis 8; Interpretation 12; Inference 8; Explanation 4 and Self-regulation 15.

Table 3. P-values for both the experimental and the control groups.

\begin{tabular}{cccc}
\hline $\begin{array}{c}\text { Critical thinking } \\
\text { aspects }\end{array}$ & $\begin{array}{c}\text { P value-Pretest For difference } \\
\text { between the two groups }\end{array}$ & $\begin{array}{c}\text { P value-Posttest For differences } \\
\text { between the two groups }\end{array}$ & $\begin{array}{c}\Delta \text { P values for overall differences } \\
\text { between the two groups }\end{array}$ \\
\hline Evaluation & 0.201 & $<0.001$ & $<0.00$ \\
Analysis & $<0.001$ & $<0.001$ & 0.002 \\
Interpretation & 0.051 & $<0.001$ & $<0.001$ \\
Inference & 0.042 & $<0.001$ & $<0.001$ \\
Explanation & 0.54 & $<0.001$ & $<0.001$ \\
Self-regulation & 0.895 & $<0.001$ & 0.001 \\
& & $\mathrm{P}(\mathrm{E}>\mathrm{C})$ & "P $(\Delta \mathrm{E} \gg \Delta \mathrm{C})$ " \\
\hline
\end{tabular}

$\mathrm{E}=$ experimental group; $\mathrm{C}=$ control group.

six main critical thinking concepts. This indicates that the difference in the mean scores in the pretest and posttest of the experimental group is significantly but also substantially higher than the difference in the mean scores of the control group in all the six critical thinking concepts. In addition to Table 2, the p-values for the experimental and control groups are indicated in Table 3. They serve as indicators for the significant impact of the educational programme on the performance of the participants in the experimental group.

The analysis of the p-values of the two groups as indicated in Table 3 indicated that in all six critical thinking skills a significant difference occurred in the mean scores of the experimental group. Owing to the fact that the posttest was written directly after 
completion of the educational programme, before exposure to any external influences, the researcher reached the conclusion that the difference was the result of the success of the educational programme.

Comparison of the post-test means scores of the experimental group and control group:

The mean scores of the posttest of the experimental group were compared with the mean scores of the posttest of the control group. A difference was observed between the mean scores of the posttest of the experimental group and the mean scores of the posttest of the control group. The mean scores of the post-test of the experimental group were significantly higher than the mean scores of the posttest of the control group.

From these findings it follows that the experimental group has probably developed through the facilitation of the educational programme. Hypothesis 3 tested as follows.

\section{Hypothesis 3:}

$\mathrm{Ho}_{3}$ is rejected in favour of $\mathrm{Ha}_{3}$ on the $2.5 \%$ level of significance $(\mathrm{P} \leq 0.001)$ in all the six main critical thinking concepts. This indicates that the mean scores of the posttest of the experimental group are significantly higher than the mean scores of the posttest of the control group in all the six critical thinking concepts. These are not only significant but also substantial. This finding is derived from the fact that the differences in the mean scores for the experimental group are significantly higher than the difference in the mean scores of the posttest of the control group (see below).

It can be concluded that the difference was the result of the educational programme. The educational programme addressed the facilitating of the development of the following six main critical thinking concepts, namely interpretation, analysis, evaluation, inference, explanation and self-regulation.

In conclusion, the outcome of the differences in mean scores between the pretest and the posttest of the two groups pertaining to the six main critical thinking concepts are indicated in figure However in this chapter the examiner looks at process and merging \& integration of the findings within the chapter. Secondary examiner looks at true reflection of the content used in designing phase.

In Figure 1, the outcome of the pretest and posttest of the experimental and control groups indicating the mean scores of each group in the six main critical thinking concepts and the difference between the mean scores of the two groups are as follow:

Concept evaluation: Pretest, experimental group scored (46.2) and control group scored (48.43) while the posttest experimental group scored 57.61 and control group scored (47.48) and the difference are (11.41) for experimental group as to compared to $(-0.94)$.

Concepts analysis: Pretest, experimental group (51.09) and control group (39.15) and posttest the experimental group scored (59.24) while control group scored(40.33) and difference scored for experimental was (8.5) as to compare to (1.8) of the control group.

Concepts interpretation: Pretest, experimental group scored (43.44) and control group (39.62) and posttest the experimental group scored (53.37) while control group scored (36.16) and difference scored for experimental was (9.93) as to compare to $-3.46)$ of the control group. 


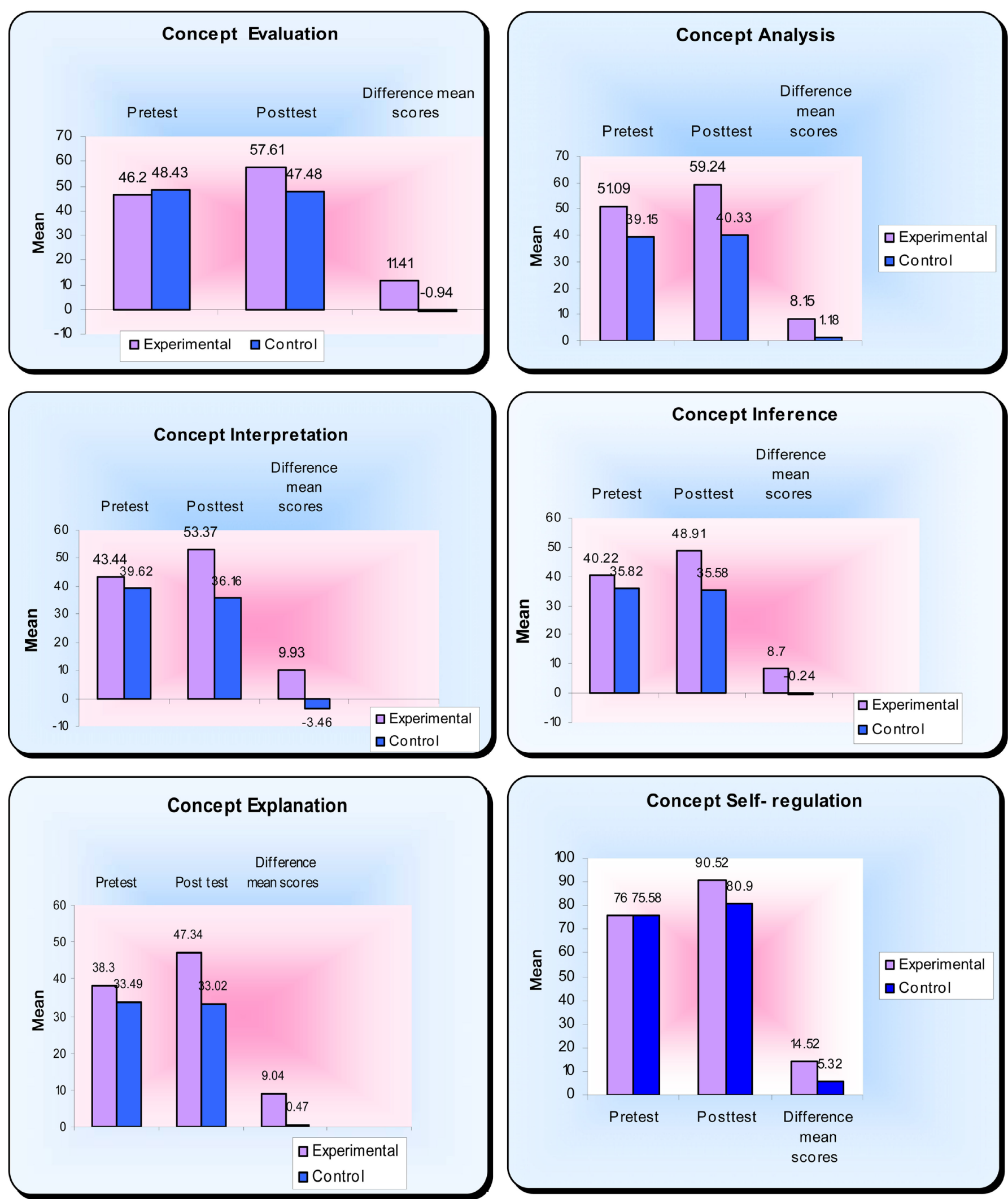

Figure 1. A graphical representation of the outcome of the pretest and posttest of the experimental and control groups indicating the mean scores of each group in the six main critical thinking concepts and the difference between the mean scores of the two groups. 
Concept inference: Pretest, experimental group scored (40.22) and control group (35.82) and posttest the experimental group scored (48.91) while control group scored (35.58) and difference scored for experimental was (8.7) as to compare to $(-0.24)$ of the control group.

Concept explanation: Pretest, experimental group (38.3) and control group (33.49) and posttest the experimental group scored (47.34) while control group scored (33.02) and difference scored for experimental was (9.04) as to compare to (0.47) of the control group.

Concept self-regulatory: Pretest, experimental group (76.00) and control group (75.58) and posttest the experimental group scored (90.52) while control group scored (80.9) and difference scored for experimental was (8.5) as to compare to (1.8) of the control group.

Discussion of the findings of the assessment of the presentation of the educational programme

The researcher was not only interested in the change in critical thinking ability of the participants, but also in the opinion of the participants regarding the content and presentation of the educational programme. Opinions were elicited through a formal assessment. Assessment is a critical component of educational practice and therefore affects educational reform efforts [40].

The educational programme assessment instrument consisted of close-ended and open-ended questions. Close-ended questions were asked about the organization and structure of the educational programme as well as the content relevance. Questions about the facilitation of the educational programme and resources supplied were included. Participants also had the opportunity to elaborate on positive and negative aspects of the educational programme and they had the opportunity to make recommendations that would be valuable to the researcher in the planning of future educational programmes.

This assessment was additional to and independent of the formal pretesting and posttesting of the educational programme. Participants completed the educational programme assessment anonymously and voluntarily. A total of 46 assessments were completed.

It was important to the researcher to obtain feedback from the participants in order to know how the participants experienced the educational programme presentation so that certain reforms could be made if necessary [41].

The assessment instrument covered and focused on the following aspects, which will be discussed in detail.

Organization of the educational programme; structure of the educational programme; content relevance; facilitator, resources; time span of the educational programme; impact of the educational programme and feedback on the utilization of the case scenario in the presentation of the educational programme

Participants were also expected to highlight their perceptions of the educational programme by elaborating on positive and negative aspects of the educational programme. 
They were given the opportunity to add recommendations. The results of the educational programme assessment will now be discussed.

Discussion of the findings of the assessment of the presentation of the educational programme

This section consisted of 7 sub-items where respondents had the opportunity to assess the presentation and content of the educational programme. All 46 respondents replied to items $1-7$, which dealt with the organization and structure of the educational programme, the relevance of the content and the input by the facilitator as well as the resources used and time allocated to the programme. The rating Scale average [the programme need more improving]; good [participants satisfied but the programme need slight improvement]; very good [no adjustment needed] and excellent [mean that they don't have any problem and happy about the programme] in terms of the structure; content; facilitation, utilization of the resources. The results for each of these items will now be discussed.

\section{Organization of educational programme}

In Figure 2, the participants expressed the following views on the organization of the educational programme on planning of the educational programme $9(19.6 \%)$ out of a possible 46 respondents rated a 5 (very good) $37(80.4 \%)$ respondents rated a 6 (excellent). Suitability of the venue 4 participants (8.7\%) found the venue good; 42 participants (91.3\%) rated the venue as excellent. Timing of each session 1 respondent (2.2\%) indicated that the timing was good, 5 respondents (10.9\%) found it very good and 40 respondents (87.0\%) rated the timing during the sessions as excellent.

\section{Structure of the educational programme}

By responding to this item, participants had the opportunity to indicate what they thought of the structure of the educational programme, which included the number of days, range of training activities and summary sessions conducted (shown in Figure 3).

In Figure 3, Participants made the following comments on the structure of the educational programme, on the question whether the number of days was appropriate for the content covered, 1 respondent (2.2\%) indicated a good, 8 respondents (17.3\%) a very good and 37 respondents $(80.4 \%)$ were of the opinion that the number of days was exactly enough and suitable for the educational programme. Respondents had to indicate whether the training activities offered were suitable and applicable. Seven respondents (15.2\%) viewed the activities as good and 39 (84.8\%) as excellent. On the question whether the summary sessions were conducted appropriately, 1 respondent $(2.2 \%)$ indicated that they were well conducted, 9 respondents (19.6\%) that they were very good and 36 respondents $(78.3 \%)$ gave them an excellent.

\section{Content of the educational programme}

The researcher/programme facilitator was interested in knowing how participants viewed the relevance of the content of the educational programme. The two items they had to respond to were relevance of the content of the educational programme to nursing and whether the content was relevant to fourth-year nursing students. Furthermore, they were expected to respond to the clarity of objectives set for the educational programme. The responses to this item are indicated in Figure 4. 


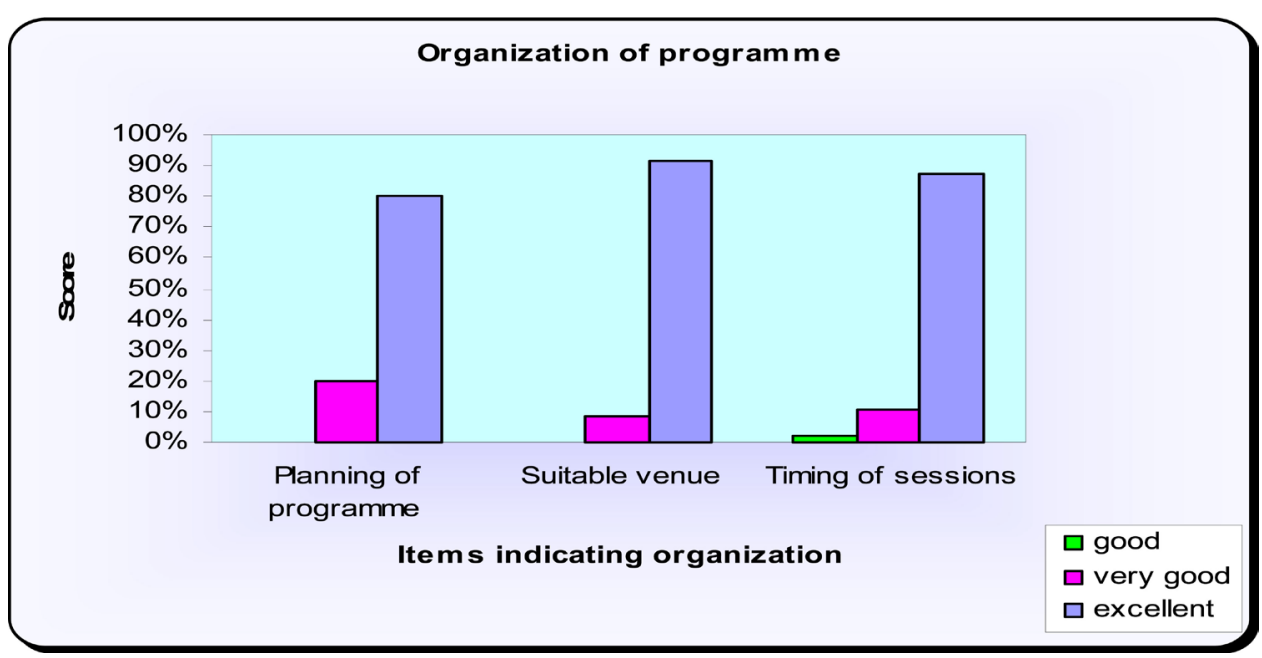

Figure 2. Organization of the educational programme.

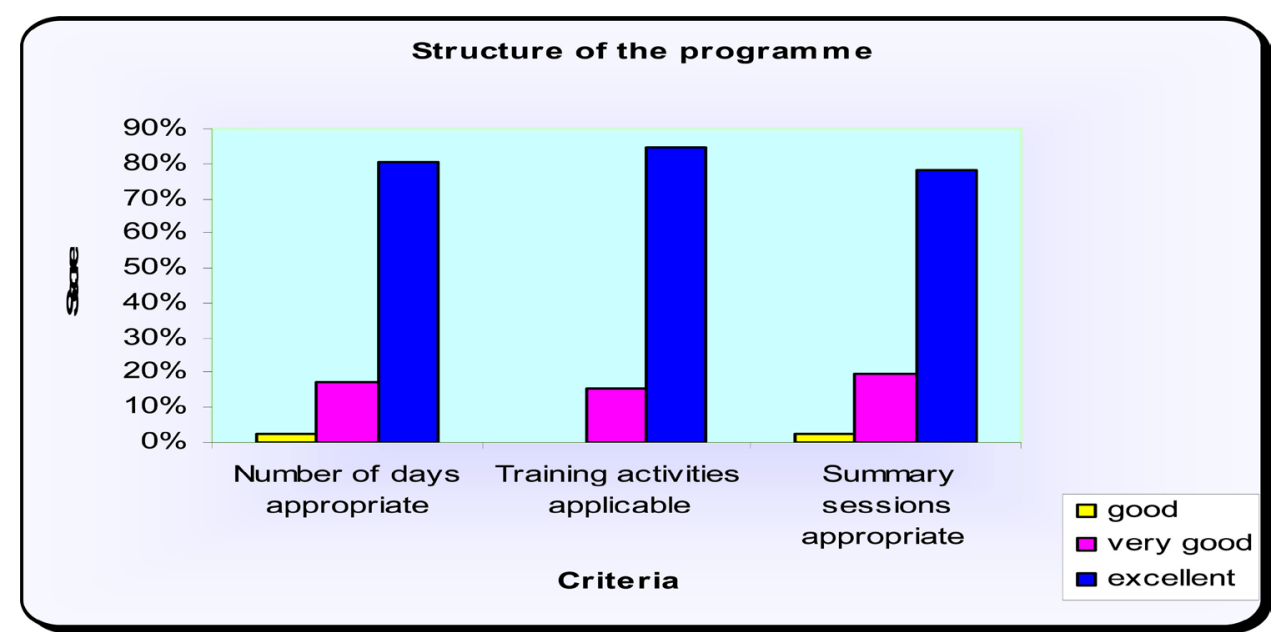

Figure 3. Structure of the educational programme.

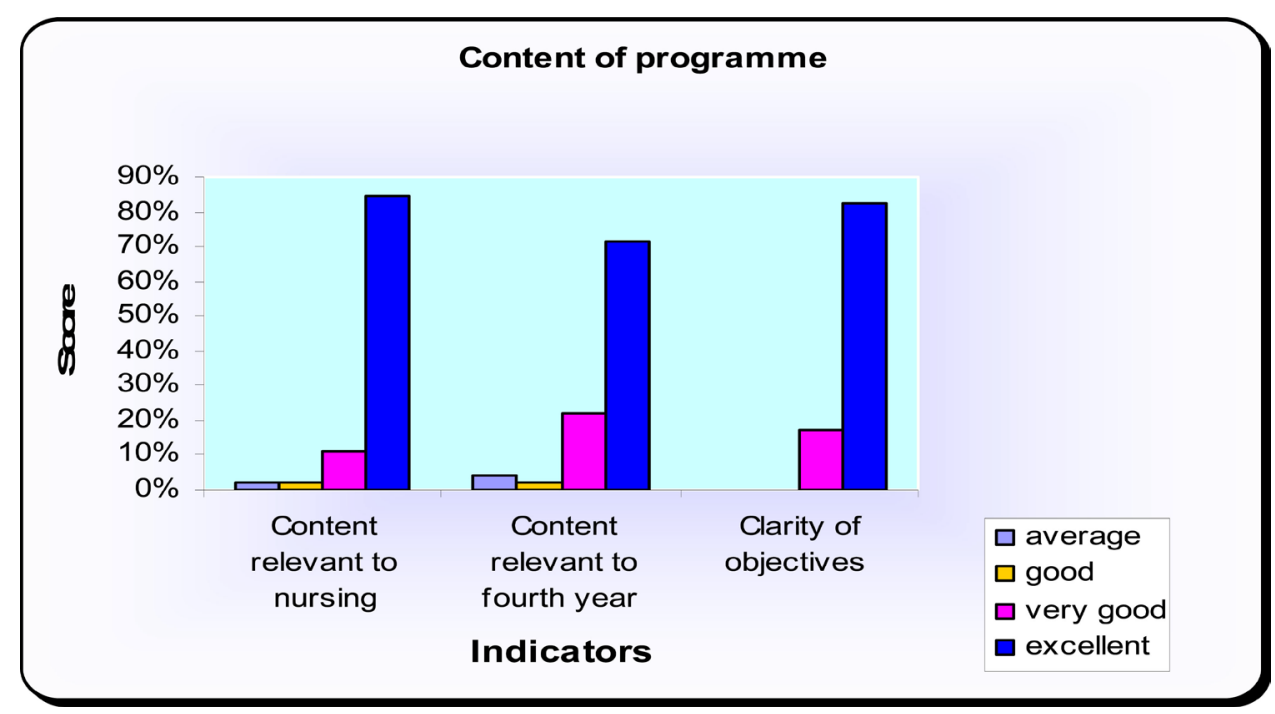

Figure 4. Content of the educational programme. 
The expression of comments by the participants can be described as follows:

One (1) respondent (2.2\%) indicated that the relevance was average, 1 respondent (2.2\%) indicated that it was good, 5 respondents (11.0\%) viewed it as very good and 39 respondents $(84.8 \%)$ felt that the content of the educational programme was very relevant and expressed this by indicating an excellent.

Regarding whether the content was relevant to the fourth-year nursing students, 2 respondent (4.4\%) indicated the relevance as average, 1 respondent $(2.2 \%)$ indicated it was good, 10 respondents (21.8\%) viewed it as very good and 33 respondents (71.7\%) felt that the content of the educational programme was very relevant to nursing and expressed this by indicating an "excellent".

Eight respondents $(17.4 \%)$ indicated that objectives set for the educational programme were very good and $38(82.6 \%)$ viewed the objectives as excellent.

\section{Facilitation of the educational programme}

The facilitation of the educational programme was a major activity and it was important for the researcher to know whether respondents had any specific perceptions about the facilitation of the educational programme. On a scale of $1-6$ the respondents had to respond to the following sub item, namely whether the facilitator had created a learning environment, whether participation by respondents was encouraged, how actively involved the respondents were during the educational programme and how the respondents' questions were answered. These responses are indicated in Figure 5.

The discussion on the findings revealed the following:

Ten respondents $(21.7 \%)$ were of the opinion that the learning environment was created in a very good way, and 36 respondents (78.3\%) rated the creation of the environment as excellent.

Seven respondents (15.2\%) stated that students were encouraged to participate in a "very good way" and for 38 respondents $(84.8 \%)$ the encouragement to participate was excellent. To the question of the extent to which the students were involved in the educational programme 14, (30.4\%) respondents indicated "very well" and 32 respondents (69.6\%) "Excellent". Two respondents (4.4\%) indicated that questions were handled

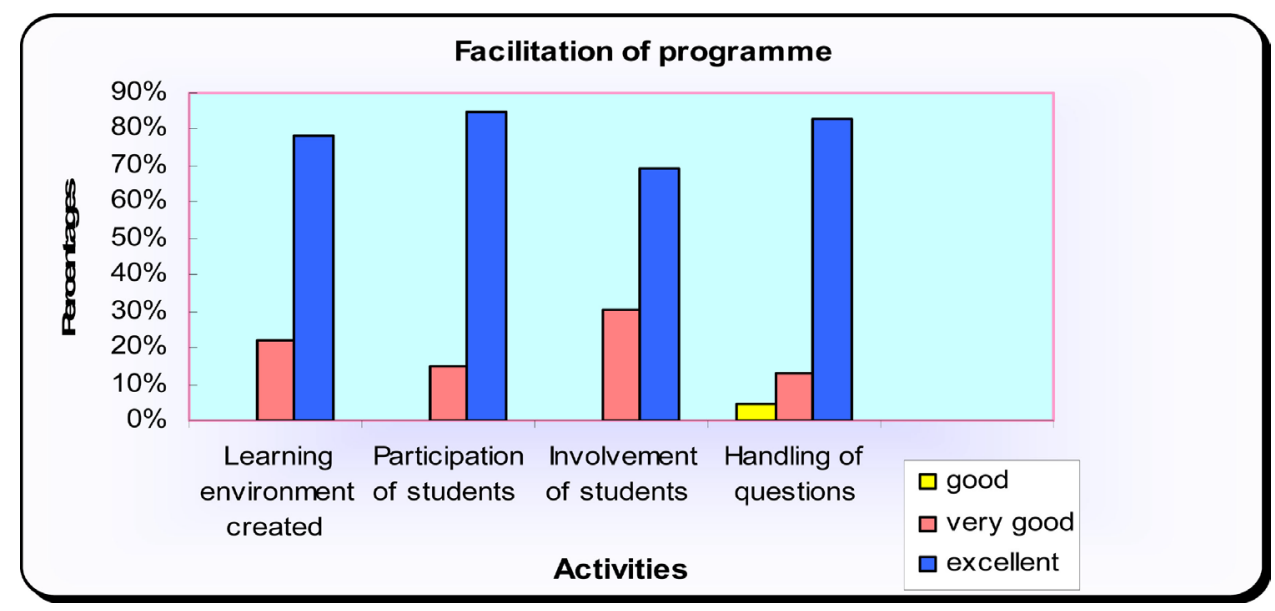

Figure 5. Facilitation of the educational programme. 
"well", 6 respondents (13.0\%) indicated "very well" and 38 respondents (82.6\%) said that questions were handled in an excellent way.

\section{Resources used during the educational programme}

An item was included where participants had an opportunity to assess the educational programme in terms of resources used during the presentation and facilitation of the educational programme. The assessment was done in terms of the course handout, whether the content was user friendly and whether the resources were sufficient. The responses to this item are reflected in Figure 6.

The description of the comments on the utilization of resources during the programme can be interpreted as follows:

On the question whether the course content was effective, 1 (2.2\%) participant indicated that it was good, 3 (6.5\%) indicated that it was very good and 42 participants (91.3\%) said it was excellent. Participants were furthermore expected to indicate whether they found the handout user friendly. One (2.2\%) participant indicated that it was good, $4(8.7 \%)$ said it was very good and 41 participants $(89.1 \%)$ indicated it was excellent. Regarding the sufficiency of the handout, 1 (2.2\%) participant indicated that it was good, 4 (8.7\%) indicated it was very good and 41 participants (89.1\%) indicated it was excellent.

\section{Time allocated for educational programme}

The literature is not clear on how long an educational programme to facilitate critical thinking ought to be. It is indicated that the length of the programme will be determined by the information that needs to be conveyed during such a programme. Participants therefore had to indicate whether the three days allowed for the implementation of the educational programme was sufficient, too long or too short and comment on the timing of each session. The opinions are indicated in Figure 7.

Out of a possible 46 responses, 41 (89.1\%) indicated that the three days were sufficient and out of a possible 45 responses 44 (97.7\%) indicated that the timing of each session was sufficient.

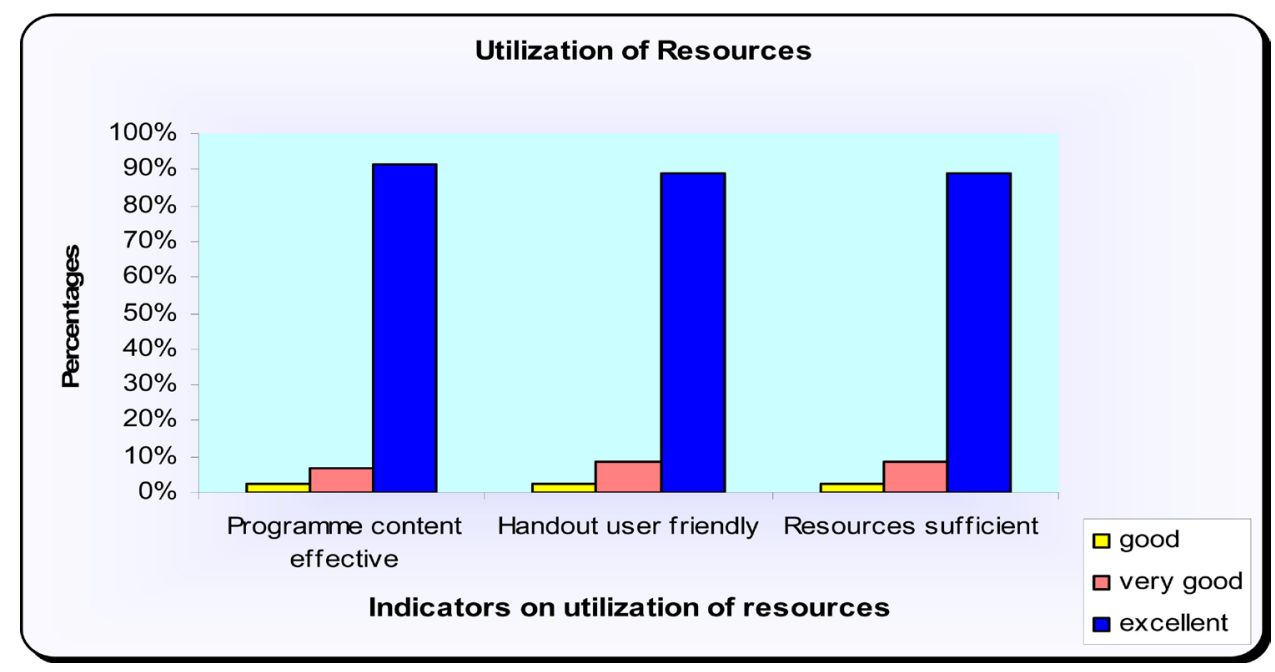

Figure 6. Utilization of resources. 


\section{Time allocation of programme}

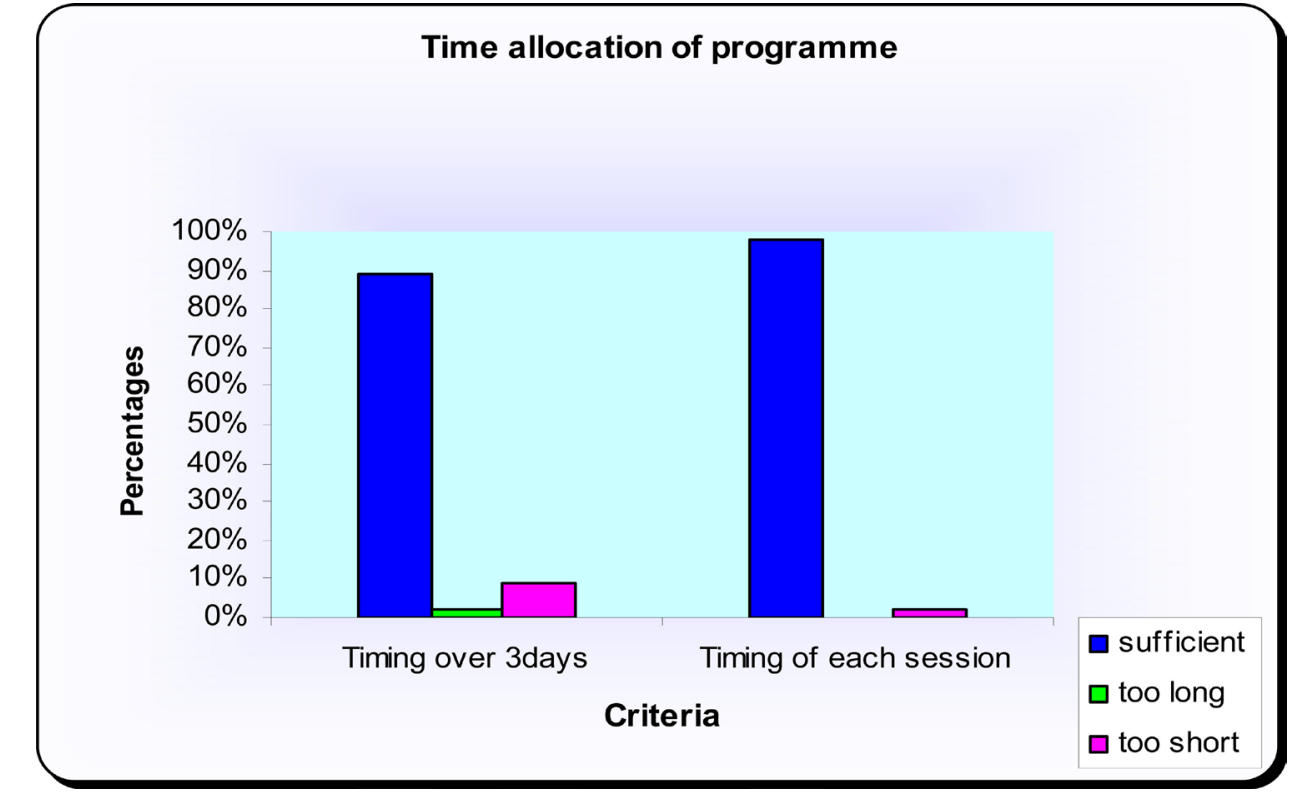

Figure 7. Time allocation for educational programme.

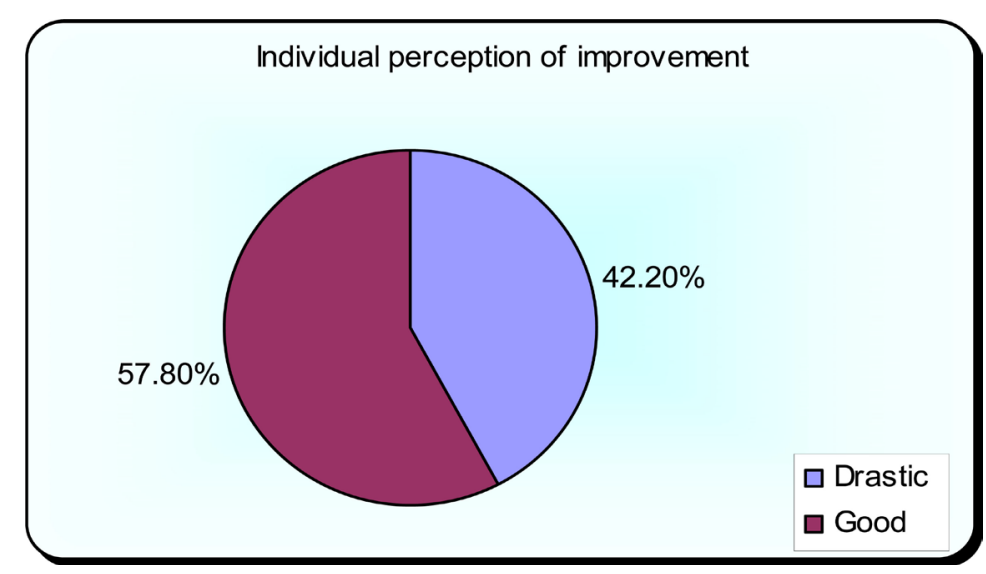

Figure 8. Individual perception of level of improvement as a result of the educational programme on critical thinking.

\section{Improvement of knowledge}

Forty-five participants responded to this question.

The researcher was interested in what the participants had to say regarding the improvement of their own knowledge. They had the opportunity to reflect about what their perception was regarding their level of improvement as indicated in Figure 8.

The analysis of the data revealed the following:

Participants could indicate on a scale of 1 - 5 how they rated their own improvement as a result of the educational programme; 1 being "no improvement" and 5 a "drastic improvement". Twenty-six participants $(57.8 \%)$ out of a possible 45 indicated that there was a good improvement in their knowledge and 19 (42.2\%) considered that there had been a drastic improvement following the educational programme. Another part of this assessment allowed for participants to elaborate on positive and negative aspects of the 
programme and, where applicable, to make recommendations regarding any part of the programme.

\section{Part 2}

This section provided for the participants to elaborate on their perceptions of the educational programme. Respondents were requested to comment on perceived possible positive and negative aspects of the educational programme. An additional request was to submit applicable recommendations about the presentation and content of the educational programme.

The participants highlighted the following positive aspects of the programme.

\section{Positive aspect on the educational programme}

The following positive comments were made about the educational programme. They have been placed verbatim.

- "This program changed the attitudes of nurses."

- "I learned a lot and changed my negativity into positivity."

- "Program was well facilitated and prepared."

- "Very informative program."

- "Great improvement of our skills."

- "I was so impressed with the program."

- "The program taught me how to think more deeply and analyze situations before actions."

The participants also had the opportunity to elaborate on any negative aspects regarding the programme. The following comments were received in this regard:

\section{Negative aspect on educational programme}

- "Time for the program was too short."

- "Although it was done a little late, it still helped me."

The last part of the assessment allowed participants to make recommendations about any aspects regarding the programme. The recommendations mostly dealt with the presentation of the programme.

\section{Recommendations on the educational programme}

The following recommendations were made:

- "It was good for us and should be done to other students in future."

- "Continue to offer this to fourth year students."

- "The program should be integrated to the $2^{\text {nd }}$ and $3^{\text {rd }}$ year/I wish it could be part of the $2^{\text {nd }}$ and $3^{\text {rd }}$ year curriculum." [13 respondents]

- "Do the program with the $3^{\text {rd }}$ years so that they can start thinking critically at an earlier level."

- "The program should be conducted to all nurses in public hospitals." [2 respondents]

- "Program to be done precisely this time after rural placement."

- "The programme assessment had some questions on the teaching strategy that was used during the presentation of the programme. The researcher used case scenarios to enhance active participation." 


\section{Conclusions}

This article dealt with the evaluation of the educational programme which was compiled and offered over a period of three days. Evaluation is the systematic process of collecting and interpreting information as a basis for decisions about learners. Evaluation of the educational programme is twofold, namely to determine whether the participants have improved on applying certain critical thinking skills and to assess their perception of the presentation of the educational programme in general.

It was concluded that this objective was achieved with the implementation and evaluation of a three-day educational programme on the facilitation of the development of critical thinking within a quasi-experimental design. Students from both the main campus (Windhoek) and the Northern Campus (Oshakati) of the Department of Nursing at the Faculty of Medical and Health Sciences of the University of Namibia were included in the quasi-experiment. Internal validity of the design was ensured by eliminating the threats to an experimental design, as referred to in their guidelines by [42]. An educational programme presentation assessment was done after the completion of the posttest of the participants who attended the educational programme. The aim of this exercise was to determine the experiences and opinions of the participants on the presentation of the educational programme and the content that was offered, as well as their opinion regarding the utilization of case scenarios as a teaching strategy for the facilitation of critical thinking.

The general assessment was that all areas of the presentation were very successful, which can be seen as support for the outcome of the hypotheses.

$\mathrm{Ho}_{1}$ is rejected in favour of $\mathrm{Ha}_{1}$ on the $5 \%$ level of significance. In four of the concepts no significant difference in the mean scores of the pretest of the experimental and control groups were found. A significant difference in the mean scores of the pretest of the experimental group and the pretest of the control group was determined in two of the six critical thinking aspects. However, the difference in the mean scores of the posttest of the experimental group and the mean scores of the posttest of the control group was also significantly and substantially higher.

$\mathrm{Ho}_{2}$ is rejected in favour of $\mathrm{Ha}_{2}$ on the $2.5 \%$ level of significance $(\mathrm{P}<0.001)$ in all the six main critical thinking concepts. This indicates that the difference in the mean scores in the pretest and posttest of the experimental group is significantly but also substantially higher than the difference in the mean scores of the control group in all the six critical thinking concepts.

$\mathrm{Ho}_{3}$ is rejected in favour of $\mathrm{Ha} 3$ on the $2.5 \%$ level of significance $(\mathrm{P} \leq 0.001)$ in all the six main critical thinking concepts. This indicates that the mean scores of the posttest of the experimental group are significantly higher than the mean scores of the posttest of the control group in all the six critical thinking concepts. These are not only significant but also substantial. This finding is derived from the fact that the differences in the mean scores for the experimental group are significantly higher than the difference in the mean scores of the posttest of the control group.

The general perceptions of the students were very positive and some of their general 
recommendations regarding the educational programme are included the following verbatim comments: the educational programme should be done to other students in future; the educational programme is of great importance and should be given to all 4 th years; the educational programme should be integrated to the 2nd and 3rd year; the educational programme should be conducted to all nurses in public hospitals; continue to teach our fellow students behind us, using the six concepts; the educational programme should be one of the nursing modules; nurses in the hospital should be given in-service training so as to improve their skills and this will help Namibian nurses to improve nursing image and the educational programme should not stop but continue then nursing care will improve.

It is concluded that not only did the educational programme make a significant difference in the scores of the students regarding the application of their critical thinking skills, but it was also positively accepted by them.

\section{References}

[1] Quinn, F.M. (2000) Principles and Practice of Nurse Education. 4th Edition, Stanley Nelson, Cheltenham.

[2] Quinn, F.M. and Hughes, S.J. (2007) Quinn's Principles and Practice of Nurse Education. 5th Edition, Stanley Nelson, Cheltenham.

[3] Burnard, P. (1995) Learning Human Skills. An Experiential and Reflective Guide for Nurses. 3rd Edition, Butterworth-Heineman, Oxford.

[4] Howard College (2006) Quality Enhancement Plan: Critical Thinking... for Learning, for Earning, for Life! http://www.howardcollege.edu/pdf/abouthc/QEP/QEP_Info.pdf

[5] Conger, M.M. and Mezza, I. (1996) Fostering Critical Thinking in Nursing Students in the Clinical Setting. Nurse Educator, 21, 11-15.

http://dx.doi.org/10.1097/00006223-199605000-00005

[6] Robinson, D.L. (1998) Clinical Decision Making for Nurse Practitioners: A Case Study Approach. Lippincott-Raven, Washington.

[7] Teekman, B. (2000) Exploring Reflective Thinking in Nursing Practice. Journal of Advanced Nursing, 31, 1125-1135. http://dx.doi.org/10.1046/j.1365-2648.2000.01424.x

[8] De Villiers, L. (1999) Criteria for a Nursing Curriculum for the New Millennium. Health SA Gesondheid, 4, 61-70. http://dx.doi.org/10.4102/hsag.v4i4.387

[9] Redding, D.A. (2001) The Development of Critical Thinking among Students in Baccalaureate Nursing Education. Holistic Nursing Practice, 15, 57-64. http://dx.doi.org/10.1097/00004650-200107000-00009

[10] Souers, C. (2002) Teaching Strategies. Nurse Educator, 27, 9-12. http://dx.doi.org/10.1097/00006223-200201000-00011

[11] Jones, R.P. (2001) Foundations of Critical Thinking. Harcourt College Publishers, Fortworth.

[12] Burnard, P. (1989) Developing Critical Thinking Ability in Nurse Education. Nurse Education Today, 9, 271-275. http://dx.doi.org/10.1016/0260-6917(89)90080-4

[13] Johns, R.M. (2002) Before Critical Thinking Comes Independent Thinking: The Special Educational Challenge of Students to Think. The Successful Professor, 1, 1-12.

[14] Van Den Berg, M.E.S. (2000) Is There a Need for critical Thinking Skills' Modules at Ter- 
tiary Level. South African Journal of Higher Education, 14, 98-107.

[15] Andolina, M. (2001) Critical Thinking for Working Students. Thomson Learning, Albany.

[16] Dillard, N. and Laidig, J. (1998) Curriculum Development: An Overview. In: Billings, D.M. and Halstead, J.A., Eds., Teaching in Nursing, Saunders, Tokyo, 69-81.

[17] Grundy, S. (1987) Curriculum: Product or Praxis. Falmer, Philadelphia.

[18] Hagerman, L.-A. (2004) Developing Critical Thinking through a Case Study Approach: A Publication of the Instructional Development Centre. Teaching at Trent, 7, 1-3.

[19] Finke, L.M. and Boland, D.L. (1998) Curriculum Designs. In: Billings, D.M. and Halstead, J.A., Eds., Teaching in Nursing, Saunders, Tokyo, 117-134.

[20] Heimlich, J.E. and Norland, E. (1994) Developing Teaching Style in Adult Education. Jossey-Bass, San Fransisco.

[21] Grotelueschen, A.D. (N.D.) Program Evaluation. In: Knox, A.B., Ed., Developing, Administering and Evaluating Adult Education, Electronic Version, Jossey-Bass, San Fransisco.

[22] Boland, D.L. (1998) Developing Curriculum. Frameworks, Outcomes and Competencies. In: Billings, D.M. and Halstead, J.A., Eds., Teaching in Nursing, Saunders, Tokyo, 135-149.

[23] Jeska, S.B. (1998) Competence Assessment Models and Methods. In: Kelly-Thomas, K.J., Ed., Clinical and Nursing Staff Development: Current Competence, Future Focus, 2nd Edition, Lippincott, Philadelphia, 121-144.

[24] Posner G.J. and Rudnitsky, A.N. (1997) Course Design. A Guide to Curriculum Development for Teachers. 5th Edition, Longman, New York.

[25] Wright, I. (2003) Is That Right? Critical Thinking and the Social World of the Young Learner. Pippin, Toronto.

[26] Jensen, E. (2006) Enriching the Brain: How to Maximize Every Learner's Potential. Jossey Bass, San Francisco.

[27] Massello, D.J. (1998) Operations Management: Administering the Program. In: KellyThomas, K.J., Ed., Clinical and Nursing Staff Development: Current Competence, Future Focus, 2nd Edition, Lippincott, Philadelphia, 337-379.

[28] Alfaro-Le Fevre, R. (2004) Critical Thinking and Clinical Judgment. 3rd Edition, Saunders, St. Louis.

[29] Bandman, E.L. and Bandman, B. (1988) Critical Thinking in Nursing. Appleton \& Lange, Connecticut.

[30] Naidoo, K. (1996) Nurturing Self-Direction in Adult Learning. South African Journal of Higher Education, 10, 86-91

[31] Oermann, M.H. and Gaberson, K.B. (1998) Evaluation and Testing in Nursing Education. Springer, New York.

[32] Richardson, V. (1998) The Diverse Learning Needs of Students. In: Billings, D.M. and Halstead, J.A., Eds., Teaching in Nursing, Saunders, Tokyo, 17-34.

[33] Follman, J. (2003) Research on Nurses' Critical Thinking. Cul de sac? Nurse Educator, 28, 255-256. http://dx.doi.org/10.1097/00006223-200311000-00005

[34] Jooste, K. (2003) Leadership in Health Services Management. Juta, Lansdowne.

[35] Canton, P. (1996) Professional Development as Transformative Learning. New Perspectives for Teachers of Adults. Jossey-Bass, San Francisco.

[36] Babbie, E. and Mouton, J. (2001) The Practice of Social Research. South Africa Oxford University Press, Cape Town.

[37] Polit, D.E. and Beck, C.T. (2006) Essentials of Nursing Research. 6th Edition, Lippincott 
Williams \& Wilkins, Philadelphia.

[38] Hicks, F.D. (2001) Critical Thinking: Toward a Nursing Science Perspective. Nursing Science Quarterly, 14, 14-21. http://dx.doi.org/10.1177/08943180122108166

[39] Khosravani, S., Manoochehri, H. and Memarian, R. (2005) Developing Critical Thinking Skills in Nursing Students by Group. The Internet Journal of Advanced Nursing Practice, 7, 3. http://www.scirp.org/(S(351jmbntvnsjtlaadkposzje))/reference/ReferencesPapers.aspx?Refe renceID $=1439725$

[40] Davis, N.T., Kumtepe, E.G. and Aydeniz, M. (2007) Fostering Continuous Improvement and Learning through Peer Assessment: Part of an Integral Model of Assessment. Educational Assessment, 12, 112-135. http://dx.doi.org/10.1080/10627190701232720

[41] Carlisle, C. and Ibbotson, T. (2005) Introducing Problem-Based Learning into Research Methods Teaching: Student and Facilitator Evaluation. Nurse Education Today, 25, $527-$ 541. http://dx.doi.org/10.1016/j.nedt.2005.05.005

[42] Vockell, E.L. and Asher, J.W. (1995) Educational Research. 2nd Edition, Prentice Hall, Upper Saddle River.

Submit or recommend next manuscript to OALib Journal and we will provide best service for you:

- Publication frequency: Monthly

- 9 subject areas of science, technology and medicine

- Fair and rigorous peer-review system

- Fast publication process

- Article promotion in various social networking sites (LinkedIn, Facebook, Twitter, etc.)

- Maximum dissemination of your research work

Submit Your Paper Online: Click Here to Submit

Or Contact service@oalib.com 